Jap. J. M. Sc. \& Biol., 9, 117-120, 1956

\title{
THE DETERMINATION OF POTASSIUM AND SODIUM CONTENT IN VARIOUS NORMAL HUMAN ORGANS ${ }^{1)}$
}

\author{
TAKAWO OHTSU2) \\ Kanto Communication Hospital, Tokyo3)
}

(Received: June 30th, 1956)

Normal values of radioactivity in human organs were strongly needed in the preceding paper (Egashira and Sakurabayashi, 1956), especially the value of potassium content. Not enough reliable data has been found so far to calculate the radioactivity of potassium on the basis of its content. Therefore, the author intended to determine the potassium and sodium content of several human organs, such as liver, lung, heart, spleen, kidney and brain by flame photometry.

\section{EXPERIMENTAL}

Preparation of samples: Corpses used in this work, obtained from the Tokyo-To Medical Examiner's Office, were listed as sudden death and presumed to have been normal Japanese. Details of the preparation of the samples were given in the preceding paper; by Egashira and Sakurabayashi (1956). Percentage of ash was about one percent of wet organ weights. These varied in color from white to light brown. Samples (18-22 $\mathrm{mg}$ ) were weighed on a semi-microbalance and were dissolved in $10 \mathrm{cc}$ of $6 \mathrm{~N}$ hydrochloric acid. Five out of 77 samples dissolved incompletely were omitted from the experiment; six other samples were discarded, because they were too hydroscopic to be weighed. The acid solution ranged in color from light yellow to yellow, possibly depending on the concentration of iron in the organs.

Flame photometry: A Beckman model DU quartz spectrophotometer equipped with a model 9200 flame photometry attachment and photomultiplier circuit was used. The instrument was allowed to stabilize before any analytical data was taken and three to five readings were taken on each sample. Potassium and sodium were determined at $768 \mathrm{~m} \mu$ and $589 \mathrm{~m} \mu$, respectively. The pressure of the oxygen was 14 psi and that of the hydrogen was 8 psi.

Standard solution and the determination of potassium and sodium: Care was taken to insure the presence of the same elements in the standard solution as was present in the samples. The composition was as follows:

1) This paper was read in the annual meeting of the Chemical Society of Japan, Tokyo, April 4, 1955.

2)大津毅 Present address: Department of Biochemistry, The University of Texas,

M. D. Anderson Hospital and Tumor Institute, Houston, Texas, U.S.A.

3)関東逓信病院 
Potassium chloride

Sodium chloride

Calcium carbonate

Ammonium phosphate
$26.6 \mathrm{mg}$ as $\mathrm{K}$

$27.4 \mathrm{mg}$ as $\mathrm{Na}$

$2.1 \mathrm{mg}$ as $\mathrm{Ca}$

$32.0 \mathrm{mg}$ as $\mathrm{P}$

These were dissolved in $100 \mathrm{cc}$ of $6 \mathrm{~N}$ hydrochloric acid. Calcium carbonate, potassium chloride and sodium chloride were Merck reagent grade; the latter two were dried at $100^{\circ} \mathrm{C}$ for 2 hours before weighing. The ammonium phosphate was Mallinckrodt ACS Standard. With the aid of a specially calibrated micropipette, $0.1 \mathrm{cc}$ of standard or sample stock solution was diluted with $4.9 \mathrm{cc}$ of demineralized water and placed in $5 \mathrm{cc}$ beakers for flame photometry; the solutions were atomized directly into the flame. Distilled water which had been treated with inon-exchange resin and then
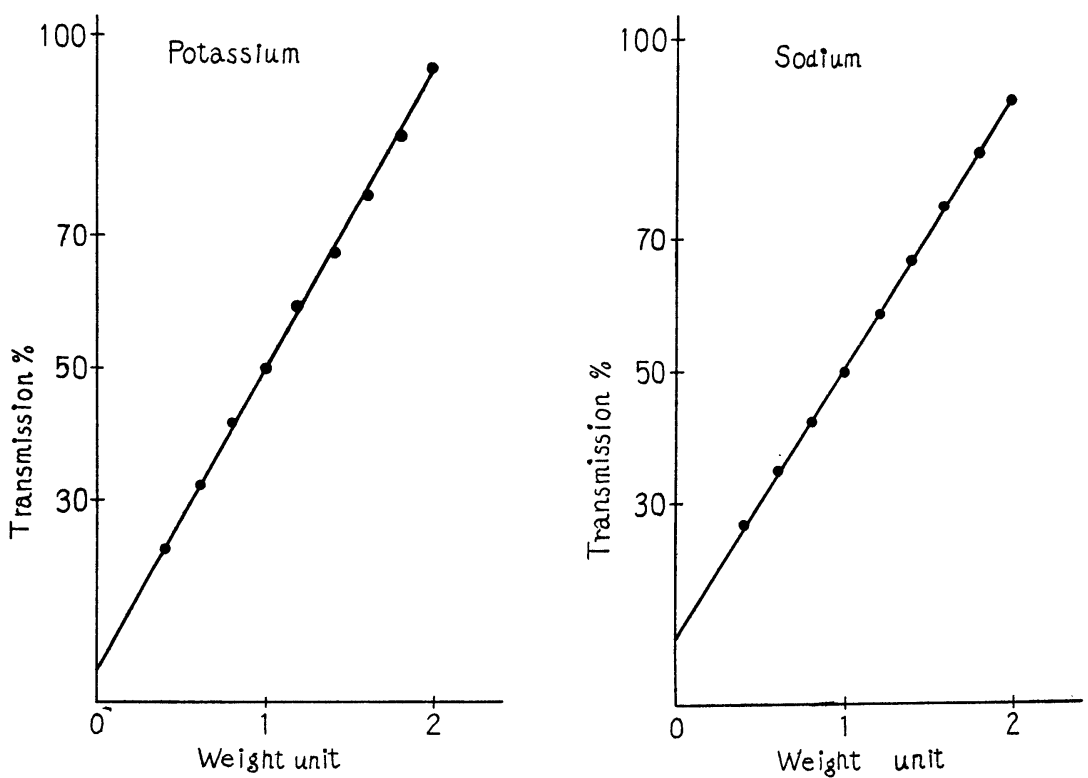

Fig. 1. The linear relationship between transmission percentage and the amount of the standard solution for potassium and sodium.

Ordinate indicates the concentration of standard solution units. 1 unit means $2.66 \mathrm{mg}$ of potassium and $2.74 \mathrm{mg}$ of sodium respectively.

stored in a tightly stoppered polyethylene bottle was used. All glass-wares used in this experiment were coated with Desicote (Beckman) of silicon-resin. The instrument was set at $50 \%$ transmission for the standard solution which was equivalent to the average value of the samples; linear relationship then existed between $30 \%$ and $70 \%$ transmission (Fig. 1). Transmission percentage will show directly the amount of potassium and sodium contained in the sample solution (see Fig. 1), when compared with the amount in the standard solution. One unit in the ordinate in Fig. 1 means $2.66 \mathrm{mg}$ of potassium and $2.74 \mathrm{mg}$ of sodium, respectively.

\section{RESUlts AND Discussion}

Results were shown in Table 1.

After the results of preliminary experiments, the composition of the standard 
solution used in this experiment was made as similar as possible to the ashes of the various organs. Therefore, the mutual interference of potassium and sodium with each other and the interference of calcium could be canceled out. The sample solution contained no organic substances so that no enhancement of the value by organic solvent nor the interference of nonspecific organic substances was observed (Kingsley et al., 1952). Mendenhall et al. (1953) gave the value of $42.5 \mathrm{mEq}$. and $74.1 \mathrm{mEq}$ per $\mathrm{kg}$ blood-free wet lung for potassium and sodium, respectively, by flame photometry, showing the value of $1.70 \mathrm{~g}$ and $1.66 \mathrm{~g}$ per $\mathrm{kg}$ wet lung for potassium and sodium, respectively. They did not give values for any other organs. The data obtained here gives the value of 1.05 and $1.57 \mathrm{~g}$ per $\mathrm{kg}$ wet weight of lung for potassium and sodium, respectively,

Table 1. Potassium and sodium content in various human organs

\begin{tabular}{|c|c|c|c|c|c|}
\hline \multirow{2}{*}{ Organ } & \multirow{2}{*}{$\begin{array}{l}\text { Number } \\
\text { of cases }\end{array}$} & \multicolumn{2}{|c|}{ Potassium* $(\%)$} & \multicolumn{2}{|c|}{ Sodium* $(\%)$} \\
\hline & & Mean & $\begin{array}{l}\text { Standard } \\
\text { deviation }\end{array}$ & Mean & $\begin{array}{l}\text { Standard } \\
\text { deviation }\end{array}$ \\
\hline Liver & 10 & 15.24 & 1.73 & 10.77 & 1.93 \\
\hline Heart & 10 & 20.31 & 3.11 & 10.33 & 2.27 \\
\hline Lung & 10 & 11.89 & 2.77 & 17.78 & 3.19 \\
\hline Spleen & 12 & 18.25 & 1.67 & 8.53 & 2.70 \\
\hline Kidney & 12 & 11.78 & 1.90 & 17.71 & 2.63 \\
\hline Brain & 12 & 17.06 & 2.97 & 9.89 & 1.85 \\
\hline
\end{tabular}

*Figures are percentage against the total ash of the organ

being calculated from the ratio of the amount of ash to the wet weight of organs. The reasons for the difference between the data of Mendenhall et al. and of the authors remains obscure. However, a partial explanation may be in the fact that the specimens used in this study were not free of blood and the amount of blood in each specimen was unknown. Other comparisons cannot be made, because there is not sufficient data.

Recently Uyeno and Ohta (1955) described much higher content of potassium in several human organs: $29,30,30,33,28$ and $31 \%$ of potassium for liver, heart, lung, spleen kidney and brain respectively on the basis of the amount of ash. This differs from the present data and also contradicts the radioactivity of potassium remaining in the ash shown in the preceding paper by Egashira and Sakurabayashi (1956).

\section{SUMMARY}

Potassium and sodium content of Japanese normal human organs were determined by flame photometry. The organs examined were liver, heart, lung, 
spleen, kidney and brain. Results were shown in Table 1.

I wish to express my thanks to Dr. D. Mizuno, Chief of Department of Chemistry, National Institute of Health, Tokyo for valuable suggestions and advices and thanks are also due to Dr. Y. Egashira, Chief of Department of Pathology, National Institute of Health, for his generous proposal to give these samples for this work and to Dr. Tomas C. Jefferis, Chief of Chemistry, 406 Medical General Laboratory, Tokyo, for reagents used in this work and helpful advice.

\section{REFERENCES}

Egashira, Y. and Sakurabayashi, T. (1956): Radioactivity of human organs. Jap. J. M. Sc. \& Biol., 9, 113-116.

Kingsley, G. R. and Schaffert, R. R. (1952) : Effect of organic solvents on the emission spectra of sodium and potassium in serum and aqueous solutions. Science, 116, $359-360$.

Mendenhall, R. M., Ramorino, P. M. and Gerastl, B. (1953) : Water, sodium, and potassium content of human, guinea pig, and rabbit lung. Proc. Soc. Exper. Biol. \& Med., 82, 318-322.

Uyeno, T. and Ohta, N. (1956): [Content of potassium and sodium in normal organs by photometry]. Jap. M. J., No. 1639, 25-27 (text in Japanese). 